\title{
Performance of Source Nursary of Pollen Parent and Cms Lines of Brassica napus L.
}

\author{
S. C. Saha \\ Plant Breeder, Research and Development Farm \\ Supreme Seed Company Ltd., Dhaka, Bangladesh \\ E-mail: sujangpb@gmail.com \\ Sabina Yeasmin \\ Department of Agronomy, Bangladesh Agricultural University \\ Mymensingh 2202, Bangladesh \\ E-mail: shalie77@yahoo.com \\ A. K. M. Aminul Islam (Corresponding author) \\ Department of Genetics and Plant Breeding \\ Bangabandhu Sheikh Mujibur Rahman Agricultural University \\ Gazipur 1706, Bangladesh \\ E-mail: aminulgpb@bsmrau.edu.bd \\ M. G. Rasul \\ Department of Genetics and Plant Breeding \\ Bangabandhu Sheikh Mujibur Rahman Agricultural University \\ Gazipur 1706, Bangladesh \\ E-mail: mdgolam60@yahoo.com \\ M. A. K. Mian \\ Department of Genetics and Plant Breeding \\ Bangabandhu Sheikh Mujibur Rahman Agricultural University \\ Gazipur 1706, Bangladesh \\ E-mail: makmian@bsmrau.edu.bd
}

Received: July 2, 2010 Accepted: September 17, 2010 doi:10.5539/jas.v3n2p114

\begin{abstract}
The study was conducted with the objective to know the performance of floral and yield characteristics of pollen and CMS parent. Significant variation was observed for flowering and yield contributing characteristics among two CMS lines $\left(Z_{1}\right.$ and $\left.Z_{2}\right)$ and 21 pollen parents. The pollen parent Nap2019 was found as early flowering whereas the parent Nap2013 was the late for first flowering. The highest length of anther was found in Nap9907 and short anther in Nap9905. Slender anther was produced by the genotype Nap2037 and bold anther was produced by the genotype Nap9907. Length of filament was the highest in Nap2012 and the lowest in Nap0130. For yield contributing characteristics, the genotype Nap9906 matured earlier than all other genotypes while the maximum duration took by Nap2013. The longest inflorescence was found in the genotype Nap2001 and the smallest in Nap9906. The highest number of siliqua per plant was counted in Nap2066 and it was the lowest in
\end{abstract}


Nap9906. Wide variability in respect of number of seeds per siliqua was exhibited among the genotypes and it was the lowest in Nap9901 and the highest in Nap94006. In case of 1000-seed weight, the genotype Nap2022 produced larger seeds and the genotype Nap9907 produced smaller seeds. The highest seed yield per plant was recorded in the genotype Nap2066 and the lowest in Nap9905. In case of $\mathrm{CMSZ}_{1}$ and $\mathrm{CMSZ}_{2}, 50 \%$ plants were flowered within 45 days after sowing. The CMS plant produced small, slender anther with shorter filament compare to pollen parents. The out crossing rate of $\mathrm{CMSZ}_{1}$ and $\mathrm{CMSZ}_{2}$ was $40.31 \%$ and $47.96 \%$, respectively. Time required for days to $80 \%$ maturity of $\mathrm{CMSZ}_{1}$ and $\mathrm{CMSZ}_{2}$ were about 106 days. The number of siliqua per plant was found the highest in $\mathrm{CMSZ}_{1}$ and the lowest in $\mathrm{CMSZ}_{2}$. The average number of seeds per siliqua and seed yield per plant was recorded the highest in $\mathrm{CMSZ}_{1}$ and the lowest in $\mathrm{CMSZ}_{2}$. The pollen parent with desirable performance and CMS parents $\mathrm{CMSZ}_{2}$ having higher out crossing rate can be used for future Brassica napus hybrid breeding program.

Keywords: Rapeseed (Brassica napus L), Pollen parent, CMS line, Floral characteristics, Seed yield

\section{Introduction}

Rapeseed (B. napus L) play a vital role in human diet but the consumption rate of oil in Bangladesh is far below than that of balanced diet (6 g oil per day per capita). The seeds of mustard and rapeseed contain $42 \%$ oil and $25 \%$ protein (Khaleque, 1985). Recent data indicated that oil crops produces 0.16 million tons of edible oil in every year as against the total requirements of 0.5 million tons for a population of 130 million in Bangladesh (Anon., 1999 and Mondal et al., 2001). The shortage of edible oil has become a chronic problem for the nation. To fulfil the requirement, the country has to import edible oils at the cost of bigger amount of foreign exchange. The share of rapeseed and mustard was 253640 tons, which comes to 52 percent of the total edible oil production (Anon., 2007). The yield of rapeseed and mustard is generally low in Bangladesh as compared with the world average. The main problems for this low yield are the use of low yielding local indigenous cultivars, unavailability of locally developed high yielding or hybrid varieties. The present seed yield per hectare of mustard in Bangladesh is far below the level attained in the developed countries of the world (BBS, 2008). Commercial $F_{1}$ hybrid cultivars become increasingly important for oilseed crops. For commercial exploitation of hybrid technology in mustard, a cytoplasmic male sterile line (A), a maintainer line (B) and a restorer line (R) are required. Before using in hybrid seed production, these CMS lines and pollen parents need to be evaluated thoroughly for different morphological, floral and agronomic traits.

Investigations leading to the development of new CMS (Cytoplasmic Male Sterile) lines and identification of maintainer lines from the germplasm have brightened the prospects of development of commercial hybrids in Brassica (Ogura, 1968). Morph-physiological, floral and yield traits of pollen as well as CMS parent can helps to identify suitable genotypes for commercial hybrids. Extent of outcrossing on a male sterile line is influenced by its floral traits, stigma size, exertion rate, length of filament of the flower in Brassica napus (Barrett and Eckert, 1990; Dudley et al., 2007; Goodwillie et al., 2009). Therefore, the present investigation was undertaken with the objective to evaluate pollen parent and CMS lines for different morphological, floral and agronomic traits.

\section{Materials and Methods}

The research work was conducted at the experimental farm, Department of Genetics and Plant Breeding, Bangabandhu Sheikh Mujibur Rahman Agricultural University (BSMRAU), Salna, Gazipur, Bangladesh. Among twenty three genotypes, two were CMS (Cytoplasmic Male Sterile) lines (Z1 and Z2: two different cytoplasmic sources) and twenty one male parents or pollen parents (parents from where pollen collected) were used as plant materials. The pollen parent and CMS lines were grown in different row in the experimental field with row spacing of $30 \mathrm{~cm}$ between row and plant spacing of $15 \mathrm{~cm}$ within the row. The experiment was laid out in a Randomized Complete Block Design (RCBD) with three replications. Fertilizers were applied at the rate of $270,170,100,150,5 \mathrm{~kg} / \mathrm{ha}$ of Urea, TSP, MP, Gypsum and Zinc sulphate, respectively. Cowdung was applied at the rate of $10 \mathrm{M}$ ton/ha. Whole amount of cowdung TSP, MP, Gypsum, Zinc sulphate and half of Urea were applied at the time of final land preparation. The remaining urea was top dressed at 30 days after seedlings emergence. Necessary intercultural operation was taken during cropping period for proper growth and development of the plants recommended by Khaleque (1985). Thinning and first weeding was done at 10 days after emergence (DAE). The second weeding was done at 30 DAE followed by application of urea by top dressing. Irrigation was given at regular interval when necessary. For suppression of aphid population Malathion 57 EC was applied three times as foliar spray at an interval of 10-15 days after seedling emergence (Khaleque, 1985). Data were collected from five randomly selected competitive plants of each of the entries on the characters days to 1 st flowering, days to $50 \%$ flowering, number of primary branches per plant, days to $80 \%$ maturity, plant height at maturity $(\mathrm{cm})$, length of inflorescence $(\mathrm{cm})$, number of siliqua per plant, length of 
siliqua $(\mathrm{cm})$, number of seeds per siliqua, 1000 -seed weight $(\mathrm{g})$, anther length $(\mathrm{mm})$, anther breadth $(\mathrm{mm})$, length of filament $(\mathrm{mm})$, length of stamen $(\mathrm{mm})$, seed yield per plant $(\mathrm{g})$. Out crossing rate $(\%)$ was determined for CMS lines using the following formula-

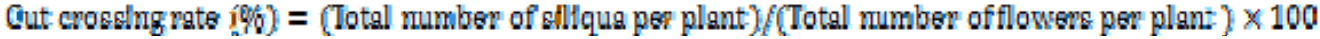

All data were analyzed using SAS statistical package version 9.01 (2008) to find out the variation among the different genotypes by F-test. Treatment means were separated by Duncan's Multiple Range Test (DMRT) at 5\% level of probability for interpretation of the results (Steel and Torrie, 1980).

\section{Results and Discussion}

\subsection{Performance of different pollen parents (B. napus genotypes)}

\subsubsection{First flowering}

Variation due to genotypes was statistically significant for this character (Table 1). In Nap2019 first flower opened at 30 days after sowing which was statistically similar with Nap9901 (30.33 days), Nap9906 (30.67 days), Nap205 (30.67 days), Nap2012 (31 days) and Nap94006 (31.67 days). The maximum duration (36.33 days) for first opening of flower was required by genotype Nap2013, which was statistically identical to Nap9908 (35 days) but significantly different to the rest of the genotypes. Genotypes having minimum days to flowering are considered good genotypes for earliness. Considering days to flowering, the genotype Nap2013 could be considered as early and quick growing cultivar.

\subsubsection{Anther length and breadth}

The mean square due to genotypes revealed significant variation existed among the genotypes for anther length and breadth (Table 1). The genotype Nap9907 and Nap9905 were found to produce the longest (2.815) and the shortest (2.075) anther, respectively. On the other hand, maximum anther breadth was observed in Nap9907 (0.918) and minimum in the genotype Nap2037 (0.697). Anther size is directly related to number of pollen grains inside anther. Genotype with larger anther contained more pollen grains which can be produced more seed per plant (Plate 1). The genotype Nap9907 with higher anther length and breadth can be produced more pollen grains inside anther. Several authors (Banga and Labana, 1985; Chen et al., 1993; Sodhi et al., 1993; Hu et al., 1992) found anther development in the pollen parent or maintainer line was normal.

\subsubsection{Length of filament}

The difference in filament length among the genotypes was observed to be statistically significant. The longest filament (8.41) was recorded in Nap0130 while the shortest (5.41) was in Nap2012 (Table 1). The shortest filament producing genotypes were Nap2001, Nap206, Nap2037, Nap205, Nap2057, Nap012, Nap94006, Nap2066, Nap2019 and Nap9905. The genotype Nap0130 produced the longest filament was found to be statistically different from rest of the twenty genotypes. Filament length can increase the cross pollination rate and improve the seed production. The genotypes with longer filament can be produced more seed compared to the genotypes with shorter filament. Sixty two percent of the genotypes under study which include 13 genotypes produced filament length varying from $6.10 \mathrm{~mm}$ to $6.80 \mathrm{~mm}$.

\subsubsection{Length of stamen}

Stamen length showed significant variation and ranged from $7.913 \mathrm{~mm}$ to $10.92 \mathrm{~mm}$ (Table 1). The longest stamen was observed in Nap0130 (10.92). The genotype Nap2012 produced the shortest (7.913) stamen and was statistically similar to the genotypes Nap9905, Nap205, Nap206, Nap2057, Nap2037, Nap94006, Nap012, Nap2022 and BARI Sarisha-8. Stamen length could be influenced the pollination and seed production in Brassica napus.

\subsubsection{0\% flowering}

Significant variation was observed for days to $50 \%$ flowering among the pollen parents under investigation. The maximum days to 50\% flowering was observed in Nap2013 (43.33) followed by Nap2057(39.33) which did not differ significantly from Nap206, Nap9907, Nap108, Nap205, Nap2001, Nap2066, Nap94006, Nap2022, Nap9908, Nap9905, Nap2037 and Nap9904. The lowest days to 50\% flowering was taken by Nap2019 (34.33) which was statistically similar to the Nap9906, Nap2012 and Nap0130. About two third of the genotypes produced 50\% flowering within 37-39 days after sowing (Table 2). The differences in days to $50 \%$ flowering might be due to the genetical factors of the genotype concerned. The genotype Nap2019 can be selected as parent during the development of short duration Brassica napus variety. 


\subsubsection{Primary branches per plant}

Marked variation was exhibited in respect of number of primary branches per plant. The maximum number (4.17) of primary branches per plant was produced by the genotype Nap9908 and the minimum (2.67) in Nap0130 (Table 2). Seventeen genotypes bearing the primary branches ranged from 3.0 to 3.8. Ghosh and Chatterjee (1988) found that the productivity of mustard per unit of area significantly affected by number of primary branches per plant in 8 different elite varieties of Indian mustard.

\section{$3.1 .780 \%$ maturity}

The analysis of variance for this character showed significant differences among the genotypes (Table 2). The minimum duration (95.67 days) for $80 \%$ maturity was required by the genotype Nap9906 followed by BARI Sarisha-8 (96.33 days) and the maximum duration by Nap2013 (109.7days). As maturity days concerned, two genotypes were taken less than 100 days for $80 \%$ maturity, exhibiting earliness.

\subsubsection{Plant height at maturity}

Analysis of variance revealed marked variation among the genotypes in respect of plant height (Table 2). Plant height at maturity varied from 81.67 to $114.7 \mathrm{~cm}$. The tallest plant was produced by the genotype Nap2022 $(114.7 \mathrm{~cm})$ followed by the genotypes Nap9908 $(105.3 \mathrm{~cm})$ and Nap9907 $(101.2 \mathrm{~cm})$. The height of the plant was found to be minimum in Nap2057 $(81.67 \mathrm{~cm})$ closely followed by Nap $9906(84.34 \mathrm{~cm})$. More than $75 \%$ genotypes attained height of plant within the range between 82.50 and $98.67 \mathrm{~cm}$. For plant height at maturity, 13 genotypes were of short stature with plant height ranged from 81.67 to $98.67 \mathrm{~cm}$ and remaining eight genotypes with long stature with plant height ranged from $100.00 \mathrm{~cm}$ to $114.7 \mathrm{~cm}$. The variation in plant height of different varieties of canola may be attributed to their genetic potential (Sana et al., 2003).

\subsubsection{Length of inflorescence}

Length of inflorescence showed a wide range of variation among the genotypes evaluated in this study. The longest (70.0) inflorescence was found in the genotype Nap2001 (Table 2) which was statistically identical with Nap2022, Nap2012, Nap9904, Nap108, BARI Sarisha-8, Nap2037, and Nap9905. The smallest inflorescence was found in Nap9906 (48.67) followed in increasing order by Nap94006, Nap9901, Nap2066, Nap205, Nap2057 and Nap012. In respect of length of inflorescence 61.9\% of the genotypes under study varied from $59.17 \mathrm{~cm}$ to $67.50 \mathrm{~cm}$. The yield increase in brassica could be attributed to increased inflorescence length as it can be accommodate more number of siliqua.

\subsubsection{Siliqua per plant}

The significant variation was observed for number of siliqua produced per plant and it was varied from 121.5 to 285.8. The highest number of siliqua per plant was produced by Nap2066 (285.8) and the other genotypes were statistically identical with that of the former being placed in the order of Nap9907 (279.1), Nap2001 (273.2), Nap108 (264.0), Nap9908 (259.8), Nap206 (201.3), Nap2037 (199.3), Nap2057 (191.5) and Nap012 (188.0). The lowest number of siliqua per plant (121.5) was produced in Nap9906 which was statistically similar to all the genotypes except Nap2066, Nap9907, Nap2001, Nap108 and Nap9908 (Table 2).

\subsubsection{Length of siliqua}

The difference in siliqua length among the genotypes was observed to be statistically significant. The longest siliqua (6.58) was produced by the genotype Nap9906 followed by Nap2037 (6.47) while the shortest by Nap0130 (5.26) followed by Nap9905 (5.27) (Table 2). The smallest siliqua producing genotype was statistically identical with those of Nap9905, Nap2001, Nap9901, Nap012, Nap2022 and BARI Sarisha-8. The longest siliqua producing genotypes was statistically similar with those of the Nap2037, Nap94006, Nap206, Nap108, Nap2057, Nap2066, Nap2019, Nap9908 and Nap9904. Wide variability in respect of siliqua length was exhibited among the genotypes.

\subsubsection{Seeds per siliqua}

Statistical difference could be detected from Table 2 regarding the number of seeds per siliqua among the various $B$. napus genotypes. It varied from 17.33 to 23.86 . The maximum number (23.86) of seeds per siliqua was recorded in the genotype Nap94006 followed by the genotypes Nap9906 (23.74) and Nap205 (23.67). The minimum number (17.33) of seeds per siliqua was found in the genotypes Nap9901 and other six genotypes were statistically identical with that of minimum seed producing genotype being placed in the order of Nap2001, Nap012, Nap0130, Nap108, Nap9905 and Nap2012. 


\subsubsection{0-seed weight}

The genotypes differ significantly in respect of 1000-seed weight (Table 2). It was observed that the genotype Nap2022 (4.64) was superior but statistically similar to the genotypes Nap2057 (4.58), BARI Sarisha-8 (4.38), and Nap108 (4.18). The minimum weight of 1000-seed were obtained in the genotype Nap9907 (3.05) which was statistically identical with Nap012 (3.20), Nap205 (3.23), Nap2013 (3.41) and Nap9905 (3.52). More than $50 \%$ of the genotypes varied from $3.62 \mathrm{~g}$ to $4.11 \mathrm{~g}$ in respect of 1000 -seed weight but they were statistically similar. Several investigators (Hashem et al., 1998; Om et al., 1998 \& Sana, et al., 2003) found significant differences for 1000-seed weight among different brassica varieties.

\subsubsection{Seed yield per plant}

The genotypes showed significant differences for seed yield per plant. The highest seed yield (19.43 g) per plant was recorded in the genotype Nap2066 followed by Nap9907 (15.48 g) that was statistically similar. Thus higher seed yield potential of these genotypes can be attributed to this parameter. The lowest seed yield per plant was produced in the genotype Nap9905 (5.90 g) that was statistically identical with all the genotypes under studied except Nap2066, Nap9907, Nap9908, Nap108 and Nap2057. Chen et al. (1995) recorded $7.2 \mathrm{~g}$ seed yield per plant in B. napus. Reddy and Reddy (1998) and Khoshnazar et al. (2000) have also been reported significant differences in seed yield in different varieties of brassica species.

\subsection{Performance of CMS lines}

From the Table 3 it was found that the first flower opened at 36.67 days after sowing in $\mathrm{CMSZ}_{1}$ and $50 \%$ plants of this line were flowered within 45 days after sowing. In case of $\mathrm{CMSZ}_{2}$ first flower opened at 32.33 days and $50 \%$ flower opened within 44.33 days after sowing. The anther length of $\mathrm{CMSZ}_{1}$ and $\mathrm{CMSZ}_{2}$ were $1.792 \mathrm{~mm}$ and $1.751 \mathrm{~mm}$, respectively. The anther breadth of $\mathrm{CMSZ}_{1}$ was $0.710 \mathrm{~mm}$ and $\mathrm{CMSZ}_{2}$ was $0.628 \mathrm{~mm}$. Chen et al. (1993, 1995) observed two type of stamen in CMS B. juncea var. tumida, stamens without an anther, and stamens with thin and degenerate anthers. The length of filament was $1.728 \mathrm{~mm}$ in $\mathrm{CMSZ}_{1}$ and $1.820 \mathrm{~mm}$ in $\mathrm{CMSZ}_{2}$. Stamen length of $\mathrm{CMSZ}_{1}$ and $\mathrm{CMSZ}_{2}$ were $3.520 \mathrm{~mm}$ and $3.571 \mathrm{~mm}$, respectively.

The CMS plants produced small and slender anther and shorter filament in compare to pollen parents (Plate 1c-e). Jones and Clarke (1943) showed male sterility associated with morphological abnormality anther and filament. Chen et al. (1993) was also found CMS line with no anthers or had silk-like structure of stamen with few pollen grains which show lowered vigour and lacking normal external structure in tuber mustard. Male sterile plants were identified by several authors (Banga and Labana, 1985; Sodhi et al., 1993; Hu et al., 1992) based on small flower, small filament, lack of anther, silk like stamen with vestigial and indehiscent anthers. Banga and Amandeep (1995) observed variation in flower traits in different nuclear backgrounds of siifolia CMS system. The out crossing rate of $\mathrm{CMSZ}_{1}$ was $40.31 \%$ and $\mathrm{CMSZ}_{2}$ was $47.96 \%$. Hackenberg and Kohler (1996) assessed variation in parental lines of rapeseed with regard to out crossing. Results showed that the partially out crossing rate was very high. Branching habit is an important character that contributes to seed yield in B. napus. Zhu et al. (1999) found that the seed production potentiality was similar between male sterile line and their male or pollen parents.

In case of CMS plants the number of primary branches per plant was found $3.67 \mathrm{in} \mathrm{CMSZ}_{1}$ and $3.50 \mathrm{CMSZ}_{2}$. Time required for days to $80 \%$ maturity of $\mathrm{CMSZ}_{1}$ and $\mathrm{CMSZ}_{2}$ were 106.67 and 105.33 , respectively. The average plant height of $\mathrm{CMSZ}_{1}$ was $95 \mathrm{~cm}$ and $\mathrm{CMSZ}_{2}$ was $108.34 \mathrm{~cm}$. The length of inflorescence was 63.34 and 65.89 in $\mathrm{CMSZ}_{1}$ and $\mathrm{CMSZ}_{2}$, respectively. The number of siliqua per plant was found 465.67 in $\mathrm{CMSZ}_{1}$ and 269.00 in $\mathrm{CMSZ}_{2}$. The longer siliqua $(6.28 \mathrm{~cm})$ was produced by $\mathrm{CMSZ}_{1}$ than $\mathrm{CMSZ}_{2}(6.28 \mathrm{~cm})$. The average number of seeds per siliqua was found in $25.94 \mathrm{~g}$ and $19.93 \mathrm{~g}$ in $\mathrm{CMSZ}_{1}$ and $\mathrm{CMSZ}_{2}$, respectively. $\mathrm{CMSZ}_{1}$ produced the smallest seeds and 1000 -seed weight was $2.97 \mathrm{~g}$. but in $\mathrm{CMSZ}_{2}$, the 1000 -seed weight was found in $3.43 \mathrm{~g}$. The seed yield per plant of $\mathrm{CMSZ}_{1}$ and $\mathrm{CMSZ}_{2}$ was recorded $17.16 \mathrm{~g}$ and $11.89 \mathrm{~g}$, respectively. Seed production capabilities of cytoplasmic male sterile cabbage derived from Ogura CMS radish was observed by Zhu et al. (1999). Seed production capabilities in cross and backcross descendants ranged from 4.1 to 20.8 seeds per pod, respectively. But seed production potentiality was similar between male sterile material and their backcross male parents (Plate 1a-b).

The genotype Nap2019 was found early for days to $1^{\text {st }}$ flowering and the genotype Nap9906 for days to $80 \%$ maturity. Anther and stamen of pollen parents were longer as compare to CMS line and its test cross progenies. The genotypes Nap9908, Nap2066, Nap94006 and Nap9906 produced the highest number of primary branches/plant, number of siliqua/plant, number of seeds/siliqua and the longest siliqua. The genotype Nap2066 produced the highest seed yield per plant (19.43 g) and it was the lowest in Nap9905 (5.90 g). 
In $\mathrm{CMS}$ plants $\left(\mathrm{CMSZ}_{1}\right.$ and $\left.\mathrm{CMSZ}_{2}\right)$ produced small and slender anther, short filament and abnormal pollen grain as compare to pollen parent. Out crossing rate was $40.31 \%$ and $47.96 \%$ in $\mathrm{CMSZ}_{1}$ and $\mathrm{CMSZ}_{2}$, respectively. Hackenberg and Kohler (1996) assessed variation in parental lines of rapeseed with regard to out crossing and found similar results.

\section{Conclusion}

From the present study it can be concluded that pollen parent with desirable performance can be test cross with CMS lines to develop new CMS lines or restorer lines depending on gene presence in their genome. On the basis of yield contributing characters and higher seed yield potential, the genotypes Nap2066, Nap9906, Nap94006 and Nap2022 are recommended for test cross with CMS line develop maintainer or restorer lines. Information on morph-physiological, floral and yield traits of pollen as well as CMS parent can helps to identify suitable genotypes for commercial hybrids. The CMS parents $\mathrm{CMSZ}_{2}$ having higher out crossing rate can be used for future Brassica napus hybrid breeding program.

\section{References}

Anonymous. (1999). FAO Production Year Book. Food and Agricultural Organization of United Nations, Rome 00108, Italy. 53, 115.

Anonymous. (2007). Statistical Year Book of Bangladesh 2006. Bangladesh Bureau of Statistics, Ministry of Planning, Government of the People's Republic of Bangladesh, Dhaka.

Banga, S.K., \& Amandeep. (1995). Assessment of siifolia cytoplasmic male sterility in Brassica juncea (L) Coss. Crop Improv., 22, 160-163.

Banga, S.S., \& Labana, K.S. (1985). Male sterility in Indian mustard (Brassica juncea L.) Cross. IV Genetics of MS-4. Can. J. Genet. Cytol., 27, 487-490.

Barrett, S.C.H, \& Eckert, C. (1990). Variation and evolution of mating systems in seed plants. In: Kawano S (ed) Biological approaches and evolutionary trends in plants. Academic Press. Harcourt Brace Jovanovich, Publishers, New York, pp 230-254.

BBS. (2008). Bangladesh Bureau of Statistics. Statistical Division, Ministry of Planning, People's Republic of Bangladesh. Dhaka, Bangladesh.

Chen, Z.J., Gao, Q.K., Wo, G.L., Wang, B.L., Sun, W.G., \& Gong, L. (1993). Morphology and genetic variation of flower of cytoplasmic male sterile in tuber mustard. Acta Agiculturae Zhejiangensis, 5(3), 172-176.

Chen, Z.J., Gao, Q.K., Wo, G.L., Wang, B.L., Sun, W.G., \& Gong, L. (1993). Morphology and genetic variation of flower of cytoplasmic male sterile in tuber mustard. Acta Agiculturae Zhejiangensis, 5(3), 172-176.

Chen, Z.J., Zhang, M.F., Wang, B.L., Dong, W.H., \& Huang, S.Q. (1995). Study of fertility and agronomic traits in cytoplasmically male sterile lines of Indian mustard. Acta Horticulturae Sinica, 22(1), 40-46.

Dudley, L.S., Mazer, S.J., \& Galusky, P. (2007). The joint evolution of mating system, floral traits and life history in Clarkia (Onagraceae): genetic constraints vs independent evolution. J Evol Biol., 20, 2200-2218.

Ghosh, R., \& Chatterjee, B. (1988). Contribution of Primary Branches to Grain Yield of Indian Mustard (Brassica juncea L.). Acta Agriculturae Scandinavica, 38(1), 49 - 57.

Goodwillie, C., Sargent, R.D., Eckert, C.G., Elle, E., Geber, M.A., Johnston, M.O., Kalisz, S., Moeller, D.A., Ree, R.H., Vallejo-Marin, M., \& Winn, A.A. (2009). Correlated evolution of mating system and floral display traits in flowering plants and its implications for the distribution of mating system variation. New Phytol, 185, 311-321.

Hackenberg, E. M., \& Kohler, W. (1996). Use of isozyme analysis in the breeding of synthetic rapeseed cultivar. Plant Breeding, 115(6), 474-479.

Hashem, A., Majumdar, M.N.A., Hamid, A., \& Hossain, M.M. (1998). Drought stress effects on seed yield, yield attributes, growth, cell membrane stability and gas exchange of synthesized Brassica napus L. J. Agron. Crop Sci., 180, 129-136.

Hu, Q., Qian, X.Z., \& Wu, X.M. (1992). A preliminary investigation of the fertility types of cytoplasm in rapeseed (Brassica napus L.). Oil Crops of China, 4, 12-14.

Jones, H., \& Clarke, A. (1943). Inheritance of male sterility in the onion and the production of hybrid seed. Proceedings of American Society of Horticultural Science, 43, 189-194

Khaleque, M.A. (1985). A Guide Book on Production of Oil crops in Bangladesh. DAE and FAO/UNDP Project BGD/79/034, 'Strengthening the Agricultural Extension Service' Khamarbari, Farmgate, Dhaka, p. 3. 
Khoshanazar, P.R., Ahmadi, M.R., \& Ghanndha, M.R. (2000). A study of adaptation and yield capacity of rapeseed (Brassica napus L.) cultivars and tines. Iranian J. Agri. Sci., 31, 341-352.

Mondal, M.R.I., Hossain, M.A., Ali, M.H., \& Begum, F. (2001). Oil seed production in Bangladesh: Constrains and opportunities. A paper presented on the $7^{\text {th }}$ Biennial Agronomy Conference on $18^{\text {th }}$ April 2001. Bangladesh Society of Agronomy. p. 45.

Ogura, H. (1968). Studies on the new male sterility in Japanese radish, with special reference to the utilization of this sterility towards the practical raising of hybrid seeds. Mem Fac Agric Kagoshima Univ, 6, 39-78.

Om, P., Das, T.K., Singh, H.B., \& Singh, N. (1999). Performance of three Brassica species as affected by time of sowing and nitrogen, I. Yield attributes and yield. Annals Agri. Res., 20, 448-454.

Reddy, C.S., \& Reddy, P.R. (1998). Performance of mustard varieties on alfisols of Rayataseema Region of Andhra Pradesh. J. Oilseeds Res., 15, 379-380.

Sana, M.A., Ali, M., Malik, A., Saleem, M.F., \& Rafiq, M. (2003). Comparative yield potential and oil contents of different canola cultivars (Brassica napus L.), Pakistan Journal of Agronomy, 2(1), 1-7.

SAS. (2008). SAS/STAT User Installation Guide for SAS ${ }^{\circledR}$ 9.1.3 Foundation for Microsoft ${ }^{\circledR}$ Windows ${ }^{\circledR}$. SAS Institute Inc., Copyright ${ }^{\circledR}$ 2003, Cary, North Carolina, USA.

Sodhi, Y.S., Pradhan, A.K., Mukhopadhyay, A., \& Pental, D. (1993). Stability of Ogura cytoplasmic male sterility in three Indian cultivars of radish (Raphanus sativus L.). Indian J. Agric. Sci., 63(7), 421-422.

Steel, R.G.D., \& Torrie, J.H. (1980). Principle and Procedures of Statistics: A Biometrical Approach. Second Edition, Mc. Graw Hill Book Co. Inc., New York.

Zhu, Y.Y., Yso, W.Y., Xiaoguang, Wu., Gong, J., Shem, F.Y., \& Jin, J. (1999). Effect of genetic background on seeding capability of cytoplasmic male sterile materials in broccoli (Brassica oleracea var. cymosa). Acta Agricultura Shanghai, 15(4), 28-30.

Table 1. Flowering characteristics of 'pollen' parents (parents from where pollen was collected)

\begin{tabular}{|c|c|c|c|c|c|}
\hline Pollen plants & $\begin{array}{l}\text { Days to } 1^{\text {st }} \\
\text { flowering }\end{array}$ & $\begin{array}{c}\text { Anther length } \\
(\mathrm{mm})\end{array}$ & $\begin{array}{c}\text { Anther breadth } \\
(\mathrm{mm})\end{array}$ & $\begin{array}{l}\text { Filament length } \\
(\mathrm{mm})\end{array}$ & $\begin{array}{c}\text { Stamen length } \\
(\mathrm{mm})\end{array}$ \\
\hline Nap012 & 32.67 & 2.45 & 0.784 & 6.00 & 8.45 \\
\hline Nap108 & 34.33 & 2.81 & 0.854 & 6.55 & 9.36 \\
\hline Nap0130 & 33.00 & 2.51 & 0.830 & 8.41 & 10.92 \\
\hline Nap205 & 30.67 & 2.44 & 0.843 & 5.80 & 8.24 \\
\hline Nap206 & 32.67 & 2.59 & 0.856 & 5.67 & 8.26 \\
\hline Nap2001 & 32.33 & 2.67 & 0.905 & 5.55 & 8.22 \\
\hline Nap2012 & 31.00 & 2.46 & 0.861 & 5.45 & 7.91 \\
\hline Nap2013 & 36.33 & 2.52 & 0.774 & 6.65 & 9.17 \\
\hline Nap2019 & 30.00 & 2.66 & 0.879 & 6.15 & 8.81 \\
\hline Nap2022 & 32.33 & 2.44 & 0.807 & 6.20 & 8.64 \\
\hline Nap2037 & 34.00 & 2.59 & 0.697 & 5.80 & 8.39 \\
\hline Nap2057 & 34.67 & 2.43 & 0.818 & 5.85 & 8.28 \\
\hline Nap2066 & 33.33 & 2.64 & 0.807 & 6.10 & 8.74 \\
\hline Nap9901 & 30.33 & 2.47 & 0.792 & 6.50 & 8.97 \\
\hline Nap9904 & 32.67 & 2.53 & 0.784 & 6.75 & 9.27 \\
\hline Nap9905 & 33.33 & 2.08 & 0.810 & 6.15 & 8.23 \\
\hline Nap9906 & 30.67 & 2.72 & 0.846 & 6.25 & 8.97 \\
\hline Nap9907 & 33.33 & 2.82 & 0.918 & 6.45 & 9.26 \\
\hline Nap9908 & 35.00 & 2.49 & 0.746 & 6.80 & 9.29 \\
\hline Nap94006 & 31.67 & 2.33 & 0.807 & 6.10 & 8.43 \\
\hline $\begin{array}{l}\text { BARI } \\
\text { Sarisa-8 }\end{array}$ & 33.00 & 2.20 & 0.751 & 6.45 & 8.65 \\
\hline F- value & $* *$ & $* *$ & $* *$ & $* *$ & $* *$ \\
\hline $\operatorname{LSD}(0.05)$ & 1.546 & 0.215 & 0.074 & 0.624 & 0.664 \\
\hline CV (\%) & 2.86 & 5.18 & 5.31 & 6.03 & 4.59 \\
\hline
\end{tabular}

Significance at $0.01(* *)$ level 
Table 2. Mean performance of 21 pollen parents (B. napus genotypes) for yield contributing characters

\begin{tabular}{|c|c|c|c|c|c|c|c|c|c|c|}
\hline Genotype & $\begin{array}{c}\text { Days to } \\
50 \% \\
\text { flowering }\end{array}$ & $\begin{array}{c}\text { No. of } \\
\text { primary } \\
\text { branches } \\
\text { /plant }\end{array}$ & $\begin{array}{c}\text { Days to } \\
80 \% \\
\text { maturity }\end{array}$ & $\begin{array}{c}\text { Plant } \\
\text { height at } \\
\text { maturity } \\
(\mathrm{cm})\end{array}$ & $\begin{array}{l}\text { Length of } \\
\text { inflorescence } \\
\quad(\mathrm{cm})\end{array}$ & $\begin{array}{c}\text { No. of } \\
\text { siliqua } \\
\text { /plant }\end{array}$ & $\begin{array}{l}\text { Length } \\
\text { of } \\
\text { siliqua } \\
(\mathrm{cm})\end{array}$ & $\begin{array}{c}\text { No. of } \\
\text { seeds } \\
\text { /siliqua }\end{array}$ & $\begin{array}{c}1000 \text { seed } \\
\text { weight }(\mathrm{g})\end{array}$ & $\begin{array}{c}\text { Seed } \\
\text { yield } \\
\text { plant } \\
(\mathrm{g}) \\
\end{array}$ \\
\hline Nap012 & 36.33 & 3.00 & 104.67 & 90.34 & 56.67 & 188.00 & 5.63 & 19.14 & 3.20 & 6.44 \\
\hline Nap108 & 38.00 & 3.00 & 104.00 & 95.67 & 65.50 & 264.00 & 6.29 & 19.67 & 4.18 & 14.03 \\
\hline Nap0130 & 36.00 & 2.67 & 105.00 & 89.17 & 59.17 & 131.67 & 5.26 & 19.33 & 3.65 & 6.13 \\
\hline Nap205 & 37.33 & 3.50 & 106.67 & 88.00 & 56.67 & 157.67 & 6.08 & 23.67 & 3.23 & 7.93 \\
\hline Nap 206 & 37.33 & 3.17 & 104.33 & 97.34 & 60.84 & 201.34 & 6.34 & 22.63 & 4.09 & 11.15 \\
\hline Nap2001 & 37.67 & 3.00 & 102.00 & 100.00 & 70.00 & 273.17 & 5.55 & 17.83 & 3.87 & 9.72 \\
\hline Nap 2012 & 35.33 & 3.17 & 101.00 & 101.17 & 66.67 & 177.17 & 6.05 & 20.09 & 3.59 & 9.70 \\
\hline Nap2013 & 43.33 & 3.17 & 109.67 & 93.50 & 59.17 & 178.33 & 5.86 & 23.64 & 3.41 & 9.63 \\
\hline Nap2022 & 39.00 & 3.34 & 105.33 & 114.67 & 67.50 & 164.34 & 5.65 & 21.67 & 4.64 & 8.70 \\
\hline Nap 9906 & 34.67 & 2.84 & 95.67 & 84.34 & 48.67 & 121.50 & 6.58 & 23.74 & 3.62 & 6.72 \\
\hline Nap 2019 & 34.33 & 2.83 & 103.33 & 88.34 & 59.17 & 182.33 & 6.17 & 20.90 & 3.68 & 6.58 \\
\hline Nap2037 & 37.67 & 3.50 & 102.67 & 97.17 & 63.34 & 199.34 & 6.47 & 21.64 & 4.04 & 10.55 \\
\hline Nap2057 & 39.33 & 3.67 & 105.33 & 81.67 & 56.67 & 191.50 & 6.26 & 22.84 & 4.58 & 12.03 \\
\hline Nap2066 & 37.67 & 3.33 & 101.67 & 90.84 & 56.50 & 285.75 & 6.24 & 22.15 & 4.12 & 19.43 \\
\hline Nap 9901 & 36.67 & 3.00 & 101.33 & 98.67 & 52.83 & 183.33 & 5.60 & 17.33 & 3.74 & 6.67 \\
\hline Nap9904 & 37.33 & 3.34 & 105.67 & 94.17 & 65.84 & 182.67 & 6.10 & 21.14 & 3.76 & 8.43 \\
\hline Nap9905 & 38.33 & 3.73 & 104.33 & 87.84 & 63.34 & 136.67 & 5.27 & 19.90 & 3.52 & 5.90 \\
\hline Nap9907 & 38.67 & 3.83 & 105.33 & 102.84 & 60.00 & 279.09 & 5.78 & 22.55 & 3.05 & 15.48 \\
\hline Nap9908 & 38.67 & 4.17 & 105.00 & 105.34 & 66.67 & 259.84 & 6.14 & 22.67 & 3.67 & 14.10 \\
\hline Nap94006 & 38.33 & 3.34 & 102.67 & 82.50 & 49.17 & 176.84 & 6.36 & 23.87 & 3.80 & 10.03 \\
\hline $\begin{array}{l}\text { BARI } \\
\text { Sarisha-8 }\end{array}$ & 36.67 & 3.17 & 96.33 & 87.83 & 64.67 & 179.00 & 5.74 & 22.77 & 4.38 & 7.52 \\
\hline F-value & $* *$ & $*$ & $* *$ & $* *$ & $* *$ & $* *$ & $* *$ & $* *$ & $* *$ & $* *$ \\
\hline $\begin{array}{l}\text { LSD } \\
(0.05)\end{array}$ & 1.786 & 0.719 & 2.218 & 15.12 & 7.687 & 85.01 & 0.421 & 2.742 & 0.430 & 4.875 \\
\hline CV (\%) & 2.88 & 13.30 & 1.30 & 9.76 & 7.71 & 26.30 & 4.25 & 7.77 & 6.86 & 29.99 \\
\hline
\end{tabular}

Significance at $0.05(*)$ and $0.01(* *)$ level

Table 3. Performance of CMS lines for flower and yield characteristics

\begin{tabular}{|l|c|c|}
\hline \multicolumn{1}{|c|}{ Characters } & $\mathrm{CMSZ}_{1}$ & $\mathrm{CMSZ}_{2}$ \\
\hline Days to ${ }^{\text {st }}$ flowering & 36.67 & 32.33 \\
\hline Days to 50\% flowering & 45.00 & 44.33 \\
\hline Anther length (mm) & 1.792 & 1.751 \\
\hline Anther breadth (mm) & 0.710 & 0.638 \\
\hline Length of filament (mm) & 1.728 & 1.820 \\
\hline Length of stamen (mm) & 3.520 & 3.571 \\
\hline Out crossing rate (\%) & 40.31 & 47.96 \\
\hline No. of primary branches per plant & 3.67 & 3.50 \\
\hline Days to 80\% maturity & 106.67 & 105.33 \\
\hline Plant height at maturity (cm) & 95.00 & 108.34 \\
\hline Length of inflorescence (cm) & 63.34 & 65.83 \\
\hline No. of siliqua per plant & 465.67 & 269.00 \\
\hline Length of siliqua (cm) & 6.28 & 5.91 \\
\hline No. of seeds per siliqua & 25.94 & 19.93 \\
\hline 1000-seed weight $(\mathrm{g})$ & 2.97 & 3.43 \\
\hline Seed yield per plant $(\mathrm{g})$ & 17.16 & 11.89 \\
\hline
\end{tabular}



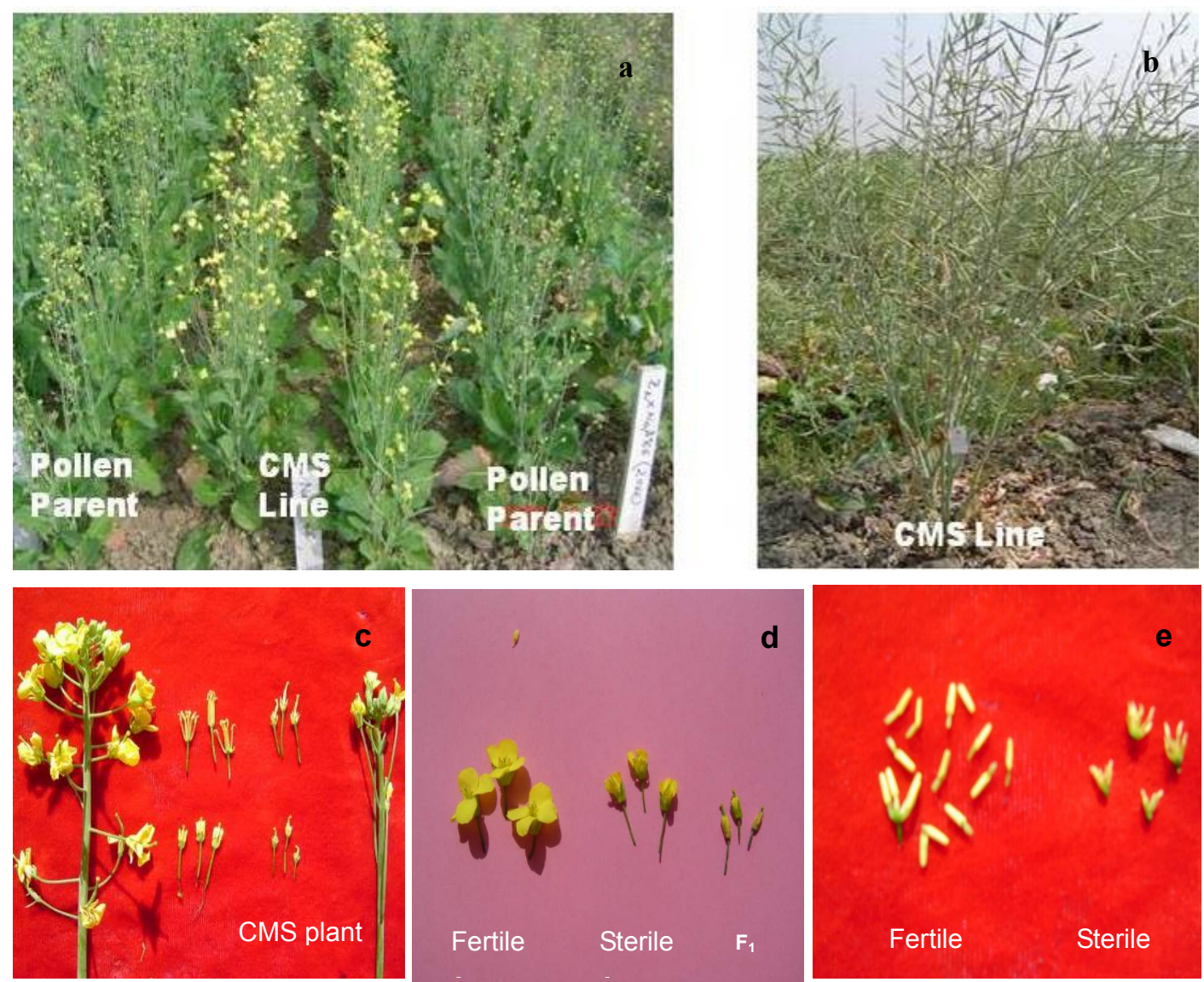

Plate 1. Showing a) flowering of pollen parent and CMS plant in the field, b) CMS plant with siliqua as a result of out crossing, c) pollen parent and CMS plant, d) flowers from pollen parent, CMS and $\mathrm{F}_{1}$ plant e) anthers from pollen parent and CMS plant 